\title{
PENGARUH PENGALAMAN KERJA, DISIPLIN KERJA, DAN KEPUASAN KERJA TERHADAP PRESTASI KERJA KARYAWAN SWAKELOLA BALAI BESAR WILAYAH SUNGAI SERAYU OPAK YOGYAKARTA
}

\author{
Inayat Hanum Indriati ${ }^{1}$, Hashfi Amga Nazhifi ${ }^{2}$ \\ Fakultas Bisnis Universitas PGRI Yogyakarta ${ }^{1,2}$ \\ inayathanum10@gmail.com
}

\begin{abstract}
This study aims to determine the effect of work experience, work discipline and job satisfaction on job performance. This research was conducted at the Serayu River Opak River Basin, Yogyakarta in 2021. This research is a quantitative study with 56 respondents and the sampling technique is simple random sampling technique. Data collection techniques were carried out by means of interviews and questionnaires. The analysis technique used is multiple linear regression analysis.The results showed that partially work experience has a significant positive effect on work performance with a sig value of 0.000 $<0.05$, work discipline has a significant positive effect on work performance with a sig value of 0.002 $<0.05$, job satisfaction has a significant positive effect on work performance with a value sig $0,000<0.05$. The results of the study simultaneously work experience, work discipline, and job satisfaction on job satisfaction with a sig value of $0.000<0.05$ and $\mathrm{F}$ count of $62.708>2.779$ (F table). The effect of work experience, work discipline and job satisfaction on work performance is indicated by the Adjusted $\mathrm{R}$ Square value of $77.1 \%$, the remaining $22.9 \%$ is influenced by other variables not examined in this study.
\end{abstract}

Keywords: work experience, work discipline, job satisfaction and job performance

\section{PENDAHULUAN}

Sumber Daya Manusia (SDM) merupakan bagian yang terpenting dalam setiap organisasi karena sebagai motor penggerak organisasi. Sumber daya manusia disetiap organisasi wajib dikelola secara maksimal agar bisa membantu mewujudkan visi dan misi organisasi tersebut (Elbadiansyah, 2019). Dalam mewujudkan hal tersebut tentunya diperlukan suatu prestasi kerja dari karyawan. Menurut Hartati (2020) prestasi kerja dapat dipengaruhi oleh faktor pengalaman kerja. Selanjutnya prestasi kerja dipengaruhi oleh faktor disiplin kerja (Hasibuan, 2003). Handoko (2001) menerangkan bahwa prestasi kerja juga dapat dipengaruhi oleh faktor kepuasan.

Menurut Mohtar (2019) pengalaman kerja yang didapat karyawan bisa memberikan pengetahuan dan keterampilan kerja yang dapat meningkatkan prestasi kerjanya. Adanya disiplin kerja akan membuat karyawan patuh dengan tata aturan yang ada di perusahaannya agar karyawan bekerja dengan nyaman sehingga hal ini dapat meningkatkan prestasi kerja karyawan (Kusumaramdhani dkk, 2019). Kepuasan kerja yang telah dicapai oleh seseorang akan berpengaruh terhadap imbalan yang diterima dan akan meningkatkan prestasi kerjanya (Rismawati, 2018).

Berdasarkan wawancara yang dilakukan peneliti di BBWSSO Yogyakarta bahwa terdapat beberapa karyawan yang pendidikannya berbeda dengan posisi kerja yang diembannya yang menyebabkan kurangnya pengetahuan dan keterampilan diposisi kerjanya tersebut. Beberapa karyawan Swakelola masih kurang dalam hal pengalaman kerja sehingga dalam meraih prestasi kerjanya masih terhambat. Terdapat beberapa karyawan terlihat belum tenang dalam bekerja, karena belum ada pengalaman kerja atau masa kerjanya belum lama. Selain masalah pengalaman 
kerja, disiplin kerja juga menyebabkan menurunnya prestasi kerja karyawan. Karena masih banyak karyawan yang tidak datang tepat waktu di tempat kerjanya. Dalam pengumpulan laporan pekerjaan karyawan juga masih sering terlambat. Selain itu ada beberapa karyawan meninggalkan kantor untuk kepentingan pribadi pada saat jam kerja. Sedangkan dalam kepuasan kerja terdapat permasalahan yaitu dalam promosi jabatan karyawan Swakelola tidak bisa mengisi jabatan setingkat manajer karena untuk mengisi jabatan tersebut harus berstatus ASN (Aparataur Sipil Negara). Karyawan selain ASN tidak bisa mengisi jabatan tersebut walaupun karyawan tersebut memiliki prestasi kerja yang bagus. Pengawasan kerja yang dilakukan oleh atasan terhadap karyawannya belum maksimal sehingga menyebabkan prestasi kerjanya menurun. Selain itu juga terdapat perbedaan pendapat antar karyawan tentang pekerjaan sehingga menyebabkan hasil kerja yang dicapai belum maksimal.

\section{Prestasi Kerja}

\section{KAJIAN TEORI}

Menurut Sutrisno (2009) prestasi kerja merupakan hasil yang dicapai oleh individu yang dinilai dari tingkah laku kerjanya dalam melaksanakan pekerjaannya. Menurut Hartati (2020) faktor prestasi kerja adalah kemampuan. Pengalaman, dan motivasi. Menurut Hasibuan (2003) faktor prestasi kerja adalah produktivitas, kedisiplinan, loyalitas, partisipasi, dan motivasi. Menurut Handoko (2001) faktor prestasi kerja antara lain motivasi, kepuasan kerja, tingkat stress, kompensasi, dan desain pekerjaan.

\section{Pengalaman Kerja}

Menurut Marwansyah (2014) pengalaman kerja merupakan suatu pengetahuan, keterampilan dan kemampuan yang dimiliki oleh karyawan yang telah didapatkan dari pekerjaan sebelumnya atau yang diperoleh semasa karyawan bekerja. Ada beberapa faktor pengalaman kerja menurut Handoko (2009), yaitu: 1) Latar belakang pribadi, dalam latar belakang pribadi ini untuk menunjukkan seseorang apa yang sudah dilakukan atau dikerjakan di waktu yang lalu meliputi pendidikan, kursus, pelatihan dan bekerja. 2) Bakat dan minat, memperkirakan kapasitas dalam keterampilan dan kemampuan seseorang. 3) Sikap dan kebutuhan, untuk meramalkan wewenang seseorang dan tanggung jawab yang diembannya. 4) Kemampuan dalam menganlisis dan manipulatif untuk mempelajari kemampuan penilaian dan analisis. Keterampilan dan kemampuan teknik seseorang sebagai tolak ukur penilaian kemampuan dalam pelaksanaan aspek teknik pekerjaan.

Menurut Foster dan Seeker (2001) ada beberapa dimensi dari pengalaman kerja, yaitu: 1) Masa kerja, jangka waktu dari seseorang yang telah dilalui selama melakukan pekerjaan. Lama waktu bekerja dapat menjadi gambaran pengalaman seseorang dalam menguasai bidang sesuai kompetensinya. Karyawan yang telah memiliki pengalaman yang cukup tidak terlalu memerlukan bimbingan dibandingkan dengan karyawan yang pengalamannya masih minim. 2) Tingkat pengetahuan dan keterampilan yang dimiliki, dalam hal ini pengetahuan mengacu pada konsep, prinsip, prosedur, kebijakan atau informasi yang lainnya yang dibutuhkan oleh karyawan. Dari pengetahuan ini mencakup kemampuan karyawan dalam menjalankan pekerjaan. 3) Penguasaan terhadap pekerjaan dan peralatan. Karyawan perlu menguasai bidang kerja yang dijalani agar dalam melakukan pekerjaan terdapat kelancaran dan minim hambatan. Peralatan harus dikuasai oleh karyawan sebagai penunjang untuk membantu menyelesaikan pekerjaan mereka. 


\section{Disiplin Kerja}

Menurut Sutrisno (2009) disiplin kerja merupakan suatu sikap yang dimiliki seorang karyawan terhadap peraturan dan ketetapan yang ada di perusahaan atau organisasi sehingga karyawan dapat beradaptasi dengan sukarela pada peraturan dan ketetapan perusahaan atau organisasi. Menurut Rivai (2009) ada empat perspektif daftar menyangkut disiplin kerja, yaitu: a) Disiplin Retributif (Retributif Discipline), yaitu berusaha memberikan hukuman bagi seseorang yang melakukan kesalahan. b) Disiplin Korektif (Corektive Discipline), yaitu berusaha untuk membantu karyawan dalam mengkoreksi perilaku atau perbuatan yang tidak tepat. c) Perspektif hak-hak individu (Individual Right Perspektif), yaitu berusaha melindungi hak-hak dasar seseorang selama seseorang tersebut melakukan tindakan yang melanggar aturan atau norma yang berlaku. d) Perspektif Utilitarian (Utilitarian Perspektif), yaitu berfokus pada penggunaan disiplin ketika saat konsekuensi tindakan disiplin melebihi dampak negatif.

Menurut Hasibuan (2013) dimensi dan indikator disiplin kerja yaitu: 1) Dimensi waktu secara efektif, dimensi pengukuran waktu secara efektif diukur menggunakan dua indikator yaitu ketaatan dan ketepatan. 2) Dimensi tanggung jawab dalam pekerjaan dan tugas, dimensi tanggung jawab dalam pekerjaan dan tugas diukur menggunakan empat indikator yaitu motivasi, loyalitas, pekerjaan dan pakaian. 3) Dimensi absensi, dimensi absensi diukur menggunakan tiga indikator yaitu jam kerja, meninggalkan tempat kerja, tidak masuk kerja dan cuti.

\section{Kepuasan Kerja}

Menurut Fattah (2017) menjelaskan bahwa kepuasan kerja merupakan suatu tingkat kebahagiaan atau sikap dan emosional dari seseorang yang positif sehingga menjadikan sebagai hasil penilaian terhadap pekerjaan yang telah dilaksanakan. Menurut Salam (2014) faktor-faktor yang mempengaruhi kepuasan kerja dibedakan menjadi 2 kelompok, yaitu: 1) Faktor intrinsik, faktor ini timbul dari dalam diri karyawan itu sendiri. Faktor ini sudah melekat di dalam diri setiap karyawan dimulai dari karyawan tersebut bekerja di tempat kerjanya. 2) Faktor ekstrinsik, faktor ini menyangkut hal-hal yang asalnya dari luar karyawan itu sendiri. Faktor ini biasanya dipengaruhi oleh kondisi lingkungan kerja, komunikasi antar karyawan, imbalan yang diterima dan sebagainya.

Menurut Robbins dan Judge (2013) dimensi dari kepuasan kerja yaitu: 1) Pekerjaan itu sendiri, sumber utama dari kepuasan karyawan dimana pekerjaan tersebut membuat tugas yang menarik, tidak membosankan dan memiliki kesempatan untuk belajar serta menerima tanggung jawab. 2) Gaji/upah, faktor multidimensi dalam kepuasan kerja. Karyawan yang menerima gaji maupun upah akan menjadi penilaian kepuasan, karena hal ini dipandang pantas dan layak. 3) Supervisi, kemampuan dari pimpinan yang memberikan bantuan terhadap karyawannya. 4) Rekan kerja, hubungan antar karyawan secara kooperatif ini salah satu sumber kepuasan kerja yang sederhana. Kelompok kerja ini bertindak sebagai sumber kenyamanan, dukungan, nasehat dan bantuan terhadap individu yang ada di kelompok kerja tersebut. 


\section{Kerangka Berfikir}

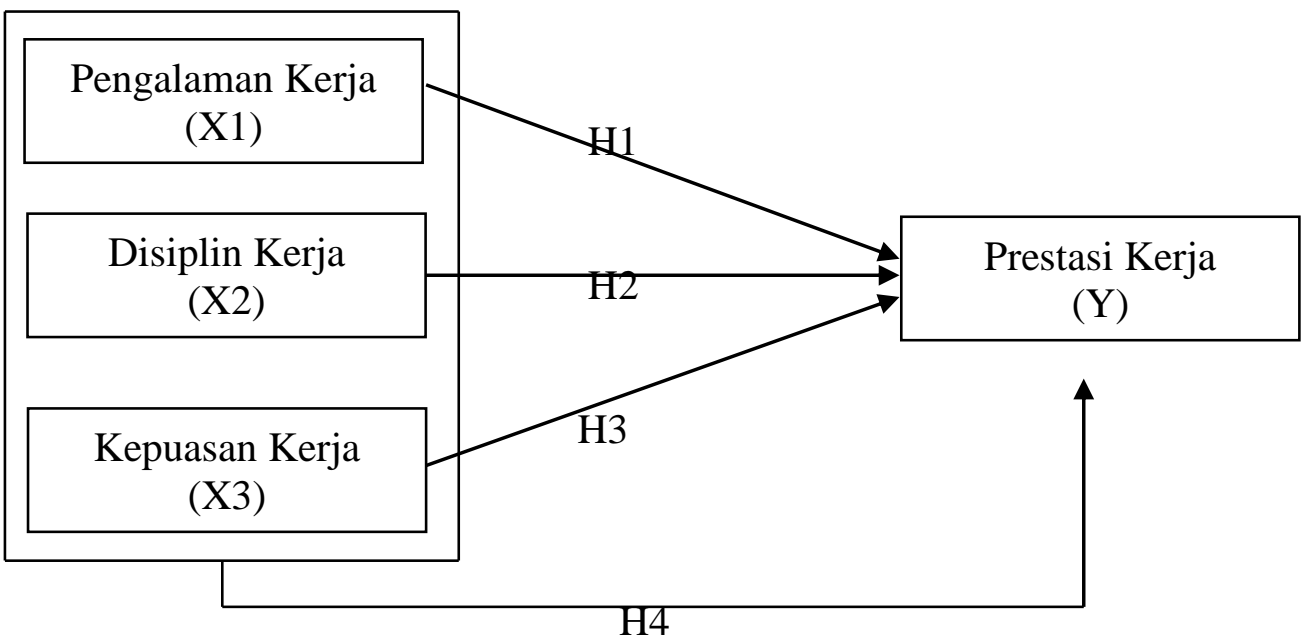

Gambar 1. Kerangka Berfikir

\section{Hipotesis Penelitian:}

Berdasarkan kerangka berfikir di atas, hipotesis dalam penelitian ini sebagai berikut:

H1 : Pengalaman kerja berpengaruh signifikan terhadap prestasi kerja

$\mathrm{H} 2$ : Disiplin kerja berpengaruh signifikan terhadap prestasi kerja

H3 : Kepuasan kerja berpengaruh signifikan terhadap prestasi kerja

H4 : Pengalaman kerja, disiplin kerja, kepuasan kerja secara simultan berpengaruh signifikan terhadap prestasi kerja

\section{METODE PENELITIAN}

\section{Teknik Analisis Data}

1. Analisis Regresi Berganda

Analisis regresi linier berganda digunakan untuk melihat hubungan variabel pengalaman kerja, disiplin kerja, dan kepuasan kerja terhadap variabel prestasi kerja karyawan. Ditulis dalam persamaan:

$\mathrm{Y}=\mathrm{a}+\mathrm{b} 1 \mathrm{X} 1+\mathrm{b} 2 \mathrm{X} 2+\ldots+\mathrm{bnXn}+\mathrm{e}$

2. Uji Signifikansi Parameter Individual (Uji Statistik t)

Uji t digunakan untuk melihat hubungan signifikan secara parsial variabel pengalaman kerja, disiplin kerja, dan kepuasan kerja terhadap prestasi kerja karyawan.

3. Uji Signifikansi Simultan (Uji Statistik F)

uji F digunakan untuk melihat pengaruh signifikan secara simultan variabel pengalaman kerja, disiplin kerja dan kepuasan kerja terhadap prestasi kerja karyawan.

4. Koefisien Determinasi 
Hasil adjusted $R$ square digunakan untuk melihat kontribusi seberapa besar yang diberikan variabel pengalaman kerja, disiplin kerja, dan kepuasan kerja terhadap prestasi kerja karyawan.

\section{Populasi dan Sampel}

Populasi dalam penelitian ini adalah karyawan Swakelola Balai Besar Serayu Opak Yogyakarta yang berjumlah 126 orang. Menurut Sugiyono (2017) simple random sampling merupakan pengambilan anggota-anggota yang ada di populasi dilakukan secara acak tanpa melihat strata yang ada di dalam populasi tersebut. Berdasarkan perhitungan rumus slovin diperoleh sampel 56 orang.

\section{HASIL PENELITIAN DAN PEMBAHASAN}

\section{Hasil Penelitian Uji Validitas}

Tabel 1. Uji Validitas

\begin{tabular}{|c|c|c|c|c|c|c|}
\hline Variabel & Item & $\frac{P}{\text { vacluee }}$ & Sigg & $\begin{array}{c}x \\
\text { hitumg }\end{array}$ & tabel & Keterangan \\
\hline \multirow{6}{*}{ Penealaman Kerja (X1) } & $8 \times 1.1$ & 0.000 & 0.05 & 0.710 & 0,2632 & Valid \\
\hline & $3 \times 1.2$ & 0.000 & 0.05 & 0.710 & 0,2632 & Valid \\
\hline & $3 \times 1.3$ & 0.000 & 0.05 & 0.635 & 0,2632 & Valid \\
\hline & $3 \times 1.4$ & 0.000 & 0.05 & 0.675 & 0,2632 & Valid \\
\hline & $3 \times 1.5$ & 0.000 & 0.05 & 0.574 & 0,2632 & Valid \\
\hline & $8 \times 1.6$ & 0.000 & 0.05 & 0.624 & 0,2632 & Valid \\
\hline \multirow{10}{*}{ Disiplin Kerja (X) } & $3 \times 2.1$ & 0.000 & 0.05 & 0.604 & 0,2632 & Valid \\
\hline & $3 \times 2.2$ & 0.003 & 0.05 & 0.389 & 0,2632 & Valid \\
\hline & $\times 2.3$ & 0.000 & 0.05 & 0.535 & 0,2632 & Valid \\
\hline & $3 \times 2.4$ & 0.001 & 0.05 & $0.42 \mathrm{~s}$ & 0.2632 & Valid \\
\hline & $\$ 2.5$ & 0.000 & 0.05 & 0.617 & 0,2632 & Valid \\
\hline & 32.6 & 0.000 & 0.05 & 0.643 & 0,2632 & Valid \\
\hline & $\$ 2.7$ & 0.000 & 0.05 & 0.509 & 0.2632 & Valid \\
\hline & $\$ 2.8$ & 0.000 & 0.05 & 0.454 & 0.2632 & Valid \\
\hline & $x 2.9$ & 0.000 & 0.05 & 0.631 & 0.2632 & Valid \\
\hline & $\times 2.10$ & 0.000 & 0.05 & 0.692 & 0.2632 & Valid \\
\hline \multirow{9}{*}{ KZepuasan $\mathbb{K}$ erja (X3) } & $\times 3.1$ & 0.000 & 0.05 & 0.589 & 0,2632 & Valid \\
\hline & $\$ \times 3.2$ & 0.003 & 0.05 & 0.729 & 0,2632 & Valid \\
\hline & $\times 3.3$ & 0.000 & 0.05 & 0.635 & 0,2632 & Valid \\
\hline & $3 \times 3.4$ & 0.001 & 0.05 & 0.782 & 0,2632 & Valid \\
\hline & $3 \times 3.5$ & 0.000 & 0.05 & 0.776 & 0.2632 & Valid \\
\hline & $3 \times 3.6$ & 0.000 & 0.05 & 0.751 & 0,2632 & Valid \\
\hline & $\$ \times 3.7$ & 0.000 & 0.05 & 0.481 & 0.2632 & Valid \\
\hline & $\$ \times 3.8$ & 0.013 & 0.05 & 0.329 & 0.2632 & Valid \\
\hline & $\$ \times 3.9$ & 0.004 & 0.05 & 0.376 & 0.2632 & Valid \\
\hline \multirow{8}{*}{ Prestasi Kerja $(Y)$} & $Y-1$ & 0.000 & 0.05 & 0.597 & 0,2632 & Valid \\
\hline & 72 & 0.000 & 0.05 & 0.710 & 0,2632 & Valid \\
\hline & $Y .3$ & 0.000 & 0.05 & 0.601 & 0,2632 & Valid \\
\hline & $7-4$ & 0.000 & 0.05 & 0.590 & 0,2632 & Valid \\
\hline & $Y .5$ & 0.000 & 0.05 & 0.581 & 0,2632 & Valid \\
\hline & \%.6 & 0.000 & 0.05 & 0.660 & 0,2632 & Valid \\
\hline & $Y .7$ & 0.000 & 0.05 & 0.631 & 0.2632 & Valid \\
\hline & Y.S & 0.000 & 0.05 & 0.662 & 0.2632 & Valid \\
\hline
\end{tabular}

Hasil uji validitas di atas menunjukkan bahwa setiap item pernyataan mempunyai nilai sig ( $p$ value) $<0,05$ dan $r$ hitung $>\mathrm{r}$ tabel. Dapat disimpulkan bahwa setiap item pernyataan dari variabel pengalaman kerja, disiplin kerja, kepuasan kerja dan prestasi kerja dinyatakan valid. 


\section{Uji Reliabilitas}

\section{Tabel 2. Uji Reliabilitas}

\begin{tabular}{|c|c|c|c|c|}
\hline Variabel & Item & $\begin{array}{c}\text { Crombaok } \\
\text { Allohu }\end{array}$ & $\begin{array}{c}\text { Standar } \\
\text { Reliabilitas }\end{array}$ & Ket \\
\hline \multirow{4}{*}{$\begin{array}{l}\text { Penzalarnan Kerja } \\
(\mathrm{XI})\end{array}$} & X1.1 & 0.896 & 0.6 & Reliabel \\
\hline & $\mathrm{X} 1.2$ & 0.896 & 0.6 & Reliabel \\
\hline & X1.3 & 0.895 & 0.6 & Rellabel \\
\hline & $\mathrm{X} 1.4$ & 0.895 & 0.6 & Reliabel \\
\hline & $\mathrm{X} 1.5$ & 0.897 & 0.6 & Reliabel \\
\hline \multirow{11}{*}{$\begin{array}{l}\text { Disiplin Rerja } \\
\text { (X2) }\end{array}$} & $\overline{X 1.6}$ & 0.897 & 0.0 & Rellabel \\
\hline & $\mathrm{X} 2.1$ & 0.897 & 0.6 & Reliabel \\
\hline & $\mathrm{X} 2.2$ & 0.898 & 0.6 & Reliabel \\
\hline & $\mathrm{X} 2.3$ & 0.898 & 0.6 & Ruliabel \\
\hline & $\mathrm{X} 2.4$ & 0.896 & 0.6 & Reliabel \\
\hline & X2.5 & 0.897 & 0.6 & Reliabel \\
\hline & $\times 2.0$ & 0.897 & 0.0 & Rellabel \\
\hline & $\mathrm{X} 2.7$ & 0.897 & 0.6 & Reliabel \\
\hline & $\mathrm{X} 2.8$ & 0.898 & 0.6 & Reliabel \\
\hline & $\overline{X 2.9}$ & 0.897 & 0.6 & Reliatel \\
\hline & $\mathrm{X} 2.10$ & 0.893 & 0.6 & Reliabel \\
\hline \multirow{9}{*}{$\begin{array}{l}\text { Kepuasan Kerja } \\
\text { (xi3) }\end{array}$} & X3.1 & 0.898 & 0.6 & Reliabel \\
\hline & $\mathrm{X} 3.2$ & 0.897 & 0.6 & Reliatel \\
\hline & $\mathrm{X} 3.3$ & 0.895 & 0.6 & Reliabel \\
\hline & $\mathrm{X} 3.1$ & 0.896 & 0.6 & Reliabel \\
\hline & $\times 3.5$ & 0.890 & 0.6 & Rellabel \\
\hline & $\mathrm{X} 3.6$ & 0.895 & 0.6 & Reliabel \\
\hline & $\mathrm{x} 3.7$ & 0.896 & 0.6 & Reliabel \\
\hline & X3.8 & 0.897 & 0.6 & Reliabel \\
\hline & X3.9 & 0.897 & 0.6 & Reliabel \\
\hline \multirow{8}{*}{ Dreatasi Kerja (V) } & Y.1 & 0.896 & 0.6 & Reliabel \\
\hline & $\mathrm{Y.2}$ & 0.890 & 0.0 & Rellabel \\
\hline & $\mathrm{Y} 3$ & 0.896 & 0.6 & Reliabel \\
\hline & $\mathrm{Y} .1$ & 0.896 & 0.6 & Reliabel \\
\hline & $Y .5$ & 0.897 & 0.6 & Rellabel \\
\hline & $Y .6$ & 0.896 & 0.6 & Reliabel \\
\hline & $\mathrm{Y} .7$ & 0.895 & 0.6 & Reliabel \\
\hline & Y.8 & 0.893 & 0.6 & Feliablel \\
\hline
\end{tabular}

Sumber: Hasil Pengolahan Data Primer 2021

Hasil uji reliabilitas di atas menunjukkan bahwa setiap variabel maupun setiap item pernyataan dari masing-masing variabel mempunyai nilai cronbach alpha >0,6. Dapat disimpulkan bahwa setiap item pernyataan dari masing-masing variabel pengalaman kerja, disiplin kerja, kepuasan kerja dan prestasi kerja dinyatakan reliabel. Hasil pengujian reliabilitas ini menunjukkan bahwa instrumen yang digunakan dalam penelitian ini konsisten dan dapat dipercaya.

\section{Uji Signifikansi Parameter Individual (Uji Statistik t)}

Tabel 3. Uji Signifikansi Parameter Individual

\begin{tabular}{|l|c|c|c|c|c|}
\hline \multicolumn{1}{|c|}{ Variabel } & $\begin{array}{c}\text { Koefisien } \\
\text { Regresi (b) }\end{array}$ & T & Sig & Ket & Kesimpulan \\
\hline Pengalaman Kerja & 0.652 & 4.530 & 0.000 & $<0.05$ & H1 Diterima \\
\hline Disiplin Kerja & 0.259 & 3.352 & 0.002 & $<0.05$ & H2 Diterima \\
\hline Kepuasan Kerja & 0.213 & 3.767 & 0.000 & $<0.05$ & H3 Diterima \\
\hline Variabe1 Dependen = Prestasi Kerja \\
Sumber: Hasil Pengolahan Data Primer 2021
\end{tabular}


Berdasarkan hasil uji tersebut diperoleh bahwa secara parsial variabel penglaman kerja, disiplin kerja, dan kepuasan kerja berpengaruh signifikan terhadap prestasi kerja karyawan, dengan melihat masing-,asing nilai signifikansi $<0,05$.

\section{Uji Signifikansi Simultan (Uji Statistik F)}

Tabel 4. Uji Signifikansi Simultan

\begin{tabular}{|c|c|c|c|}
\hline Variabel & $\mathrm{F}$ & Sig & Kesimpulan \\
\hline $\begin{array}{l}\text { Pengalaman Kerja, } \\
\text { Disiplin Kerja dan } \\
\text { Kepuasan Kerja, }\end{array}$ & 62.708 & 0.000 & H4 Diterima \\
\hline
\end{tabular}

Berdasarkan hasil uji tersebut diperoleh bahwa variabel pengalaman kerja, disiplin kerja dan kepuasan kerja secara simultan berpengaruh terhadap prestasi kerja karyawan, dengan melihat masing-masing nilai signifikansi $<0,05$.

\section{Koefisien determinasi}

\section{Tabel 5. Koefisien Determinasi}

\begin{tabular}{|c|c|c|c|c|}
\hline Model & $\mathbf{R}$ & R Square & $\begin{array}{c}\text { Adjusted } \mathrm{R} \\
\text { Square }\end{array}$ & $\begin{array}{c}\text { Std. Error of } \\
\text { the Estimate }\end{array}$ \\
\hline 1 & 0.885 & 0.783 & 0.771 & 1.443 \\
\hline
\end{tabular}

Sumber: Hasil Pengolahan Data Primer 2021

Tabel di atas menunjukkan besarnya nilai Adjusted $R$ Square adalah 0.771 hal ini berarti kontribusi variabel pengalaman kerja, disiplin kerja dan kepuasan kerja dapat menjelaskan variabel prestasi kerja sebesar $77,1 \%$ dan sisanya $22,9 \%$ dijelaskan oleh variabel lain di luar penelitian ini.

\section{Pembahasan Hasil Penelitian \\ Pengaruh Pengalaman Kerja Terhadap Prestasi Kerja}

Hasil penelitian menunjukkan bahwa pengalaman kerja berpengaruh positif dan signifikan terhadap prestasi kerja. Hal ini ditunjukkan dengan koefisien regresi sebesar 0,652 yang bernilai positif dan nilai sig sebesar 0,000. Pengaruh positif berarti bahwa pengalaman kerja mempunyai pengaruh yang searah terhadap prestasi kerja karyawan Swakelola Balai Besar Wilayah Sungai Serayu Opak Yogyakarta. Semakin baik pengalaman kerja maka akan meningkatkan prestasi kerja. Nilai signifikan di bawah 0,05 menunjukkan bahwa pengalaman kerja mempunyai pengaruh terhadap prestasi kerja karyawan Swakelola Balai Besar Wilayah Sungai Serayu Opak Yogyakarta.

Hasil penelitian ini sesuai dengan teori yang dikemukakan oleh Marwansyah (2014) pengalaman kerja merupakan suatu pengetahuan, keterampilan dan kemampuan yang dimiliki oleh karyawan yang telah didapatkan dari pekerjaan sebelumnya atau yang diperoleh semasa 
karyawan bekerja. Hasil penelitian ini juga didukung penelitian terdahulu yang dilakukan oleh Hani Nur Hotimah (2020) yang menunjukkan bahwa pengalaman kerja berpengaruh positif dan signifikan terhadap prestasi kerja.

\section{Pengaruh Disiplin Kerja terhadap Prestasi Kerja}

Hasil penelitian menunjukkan bahwa disiplin kerja berpengaruh positif dan signifikan terhadap prestasi kerja. Hal ini ditunjukkan dengan koefisien regresi sebesar 0,259 yang bernilai positif dan nilai sig sebesar 0,002. Pengaruh positif berarti disiplin kerja mempunyai pengaruh yang searah terhadap prestasi kerja karyawan Swakelola Balai Besar Wilayah Sungai Serayu Opak Yogyakarta. Semakin tinggi disiplin kerja maka akan meningkatkan prestasi kerja. Nilai signifikan di bawah 0,05 menunjukkan disiplin kerja mempunyai pengaruh terhadap prestasi kerja karyawan Swakelola Balai Besar Wilayah Sungai Serayu Opak Yogyakarta.

Hasil penelitian ini sesuai dengan teori yang dikemukakan oleh Sutrisno (2009) disiplin kerja merupakan suatu sikap yang dimiliki seorang karyawan terhadap peraturan dan ketetapan yang ada di perusahaan atau organisasi sehingga karyawan dapat beradaptasi dengan sukarela pada peraturan dan ketetapan perusahaan atau organisasi. Hasil penelitian ini sejalan dengan penelitian terdahulu yang dilakukan oleh Istiana dan Antonius Dieben Robinson Manurung (2018) yang menunjukkan bahwa disiplin kerja berpengaruh positif dan signifikan terhadap prestasi kerja.

\section{Pengaruh Kepuasan Kerja terhadap Prestasi Kerja}

Hasil penelitian menunjukkan bahwa kepuasan kerja berpengaruh positif dan signifikan terhadap prestasi kerja. Hal ini ditunjukkan dengan koefisien regresi sebesar 0,213 yang bernilai positif dan nilai sig sebesar 0,000. Pengaruh positif berarti kepuasan kerja mempunyai pengaruh yang searah terhadap prestasi kerja karyawan Swakelola Balai Besar Wilayah Sungai Serayu Opak Yogyakarta. Semakin tinggi kepuasan kerja maka akan meningkatkan prestasi kerja. Nilai signifikan di bawah 0,05 menunjukkan kepuasan kerja mempunyai pengaruh terhadap prestasi kerja karyawan Swakelola Balai Besar Wilayah Sungai Serayu Opak Yogyakarta.

Hasil penelitian ini sejalan dengan teori yang dikemukakan oleh Fattah (2017) menjelaskan bahwa kepuasan kerja merupakan suatu tingkat kebahagiaan atau sikap dan emosional dari seseorang yang positif sehingga menjadikan sebagai hasil penilaian terhadap pekerjaan yang telah dilaksanakan. Hasil penelitian ini juga didukung penelitian terdahulu yang dilakukan oleh Tumanggor (2018) yang menunjukkan kepuasan kerja berpengaruh positif dan signifikan terhadap prestasi kerja.

\section{Pengaruh Pengalaman Kerja, Disiplin Kerja dan Kepuasan Kerja terhadap Prestasi Kerja}

Hasil penelitian menunjukkan bahwa pengalaman kerja, disiplin kerja dan kepuasan kerja secara simultan berpengaruh terhadap prestasi kerja. Hal ini ditunjukkan dengan nilai sig sebesar 0,000 yang lebih kecil dari 0,05 dan F hitung sebesar 62,708 lebih besar dari F tabel yaitu 2,779. Hasil penelitian ini berarti jika pengalaman kerja, disiplin kerja dan kepuasan kerja diterapkan dengan baik di organisasi maka akan meningkatkan prestasi kerja karyawan Swakelola Balai Besar Wilayah Sungai Serayu Opak Yogyakarta sehingga tujuan organisasi akan lebih mudah tercapai.

Hasil Adjusted R Square menunjukkan sebesar 77,1\% variabel pengalaman kerja, disiplin kerja dan kepuasan kerja dapat menjelaskan variabel prestasi kerja dan sebesar 22,9\% dijelaskan 
variabel lain di luar penelitian ini seperti keahlian kerja, minat kerja, motivasi kerja dan situasi kerja (Wijono, 2010).

\section{KESIMPULAN}

Berdasarkan dari analisis data dan pembahasan hasil penelitian di Balai Besar Wilayah Sungai Serayu Opak Yogyakarta yang berkaitan dengan prestasi kerja dapat disimpulkan sebagai berikut:

1. Pengalaman kerja berpengaruh positif dan signifikan terhadap prestasi kerja Karyawan Swakelola Balai Besar Wilayah Sungai Serayu Opak Yogyakarta.

2. Disiplin kerja berpengaruh positif dan signifikan terhadap prestasi kerja Karyawan Swakelola Balai Besar Wilayah Sungai Serayu Opak Yogyakarta.

3. Kepuasan kerja berpengaruh positif dan signifikan terhadap prestasi kerja Karyawan Swakelola Balai Besar Wilayah Sungai Serayu Opak Yogyakarta.

4. Pengalaman kerja, disiplin kerja dan kepuasan kerja secara simultan berpengaruh terhadap prestasi kerja karyawan Swakelola Balai Besar Wilayah Sungai Serayu Opak Yogyakarta.

\section{Saran}

Saran yang dapat diberikan penulis adalah sebagai berikut:

1. Bagi Peneliti Selanjutnya, diharapkan memperluas variabel yang diteliti, sehingga tidak hanya menggunakan variabel pengalaman kerja, disiplin kerja dan kepuasan kerja. Karena terdapat faktor-faktor lain yang mempengaruhi prestasi kerja yang belum diteliti pada penelitian ini.

2. Bagi organisasi diharapkan melakukan upaya untuk meningkatkan pengalaman kerja para karyawannya. Hasil penelitian ini menunjukkan pengalaman kerja memiliki pengaruh yang paling besar terhadap prestasi kerja, berarti bahwa pengalaman kerja sangat penting untuk meningkatkan prestasi kerja karyawan. Balai Besar Wilayah Sungai Serayu Opak Yogyakarta sebaiknya dalam menerima karyawan penempatan posisis kerjanya disesuaikan dengan pendidikannya dan menyelenggarakan pelatihan secara berkala untuk karyawan yang belum memiliki pengetahuan, keterampilan yang memadai, serta belum memiliki masa kerja yang lama karena hal itu jika tidak diperhatikan akan menghambat prestasi kerja yang akan dicapai.Balai Besar Wilayah Sungai Serayu Opak Yogyakarta sebaiknya memperhatikan disiplin kerja karyawannya dengan melakukan pengetatan aturan-aturan standar kerja agar tidak ada lagi permasalahan seperti masuk kantor tidak tepat waktu, karyawan meninggalkan kantor pada saat jam kerja untuk kepentingan pribadi, dan mengumpulkan laporan tidak tepat waktu. Karena hal-hal tersebut akan menghambat karyawan dalam meraih prestasi kerjanya. Sedangkan dari segi kepuasan kerja, Balai Besar Wilayah Sungai Serayu Opak Yogyakarta sebaiknya memperhatikan kepuasan kerja karyawannya seperti mengganti kebijakan promosi jabatan karyawan Swakelola yang lebih fleksibel, melakukan pengawasan secara berkala kepada karyawannya agar dalam bekerja karyawan akan lebih terarah, karena hal itu akan mempengaruhi karyawan untuk meraih prestasi kerja yang akan dicapai. Dengan demikian, organisasi dapat melakukan evaluasi dan melakukan upaya untuk meningkatkan pengalaman kerja, disiplin kerja dan kepuasan kerja sehingga karyawan akan termotivasi untuk mencapai prestasi kerja yang diharapkan dan membantu dalam mencapai tujuan organisasi. 


\section{DAFTAR PUSTAKA}

Elbadiansyah. 2019. Manajemen Sumber Daya Manusia. Purwokerto: CV IRDH.

Fattah, H. 2017. Kepuasan Kerja dan Kinerja Pegawai. Yogyakarta: Elmatera.

Foster, B., \& Seeker, K. R. 2001. Pembinaan Untuk Meningkatkan Kinerja Karyawan. Jakarta: PT. Toko Gunung Agung.

Handoko, T. H. 2001. Manajemen Personalia dan Sumber Daya Manusia. Yogyakarta: BPFE Yogyakarta. . 2009. Manajemen Cetakan Duapuluh. Yogyakarta: BPEE.

Hartati, S. 2020. Gender Dalam Birokrasi Pemerintahan. Surabaya: Scopindo Media Pustaka.

Hasibuan, M. S. 2003. Manajemen Sumber Daya Manusia. Jakarta: PT. Bumi Aksara. 2013. Manajemen Sumber Daya Manusia. Jakarta: PT. Bumi Aksara.

Husein, U. (2017). Compensation analysis in relationship moderation between transformational leadership style and work environment on the employee performance. Russian Journal of Agricultural and Socio-Economic Sciences, 71(11).

Istiana, \& Dieben, A. 2018. Pengaruh Komitmen Organisasi, Disiplin Kerja, Dan Kualitas Kehidupan Kerja Terhadap Prestasi Kerja Karyawan Universitas Mercu Buana Jakarta. Jurnal SWOT, 8(2) 292-305.

Joko, S. D. (2019). National security of investment climate: a case study in the South Sulawesi region of indonesia. Russian Journal of Agricultural and Socio-Economic Sciences, 85(1).

Kusumaramdhani, A., Nurlatifah, F., dkk. (eds.). 2019. CIFET 2019 Prooceedings of the 1st conference on Islamic finance and technology. Sidoarjo: EAI Publishing.

Marwansyah. 2014. Manajemen Sumber Daya Manusia Edisi Kedua. Bandung: Alfabeta.

Mohtar, I. 2019. Hubungan Antara Motivasi Kerja dan Pengalaman Kerja dengan Kinerja Guru Madrasah. Ponorogo: Uwais Inspirasi Indonesia.

Rismawati, M. 2018. Evaluasi Kinerja: Penilaian Kinerja Atas Dasar Prestasi Kerja Beroirentasi Kedepan. Makassar: Celebes Media Perkasa.

Robbins, Judge, S. P., \& Timothy. 2013. Organizational Behavior Edition 15. New Jersey: Pearson Education.

Salam, A. 2014. Manajemen Insani Dalam Bisnis. Yogyakarta: Pustaka Pelajar.

Sulivyo, L., Siswoko, R., \& Tegor, T. (2019). The Effectiveness of Holistic Marketing and Word-ofMouth Communication on Purchasing Decision at Pt Asuransi Central Asia Branch Office of Tiang Bendera West Jakarta. International Journal of Multicultural and Multireligious Understanding, 6(1), 187-199.

Sutrisno, E. 2009. Manajemen Sumber Daya Manusia Edisi Pertama. Jakarta: Prenada Media.

Tegor, T., Yusmalina, Y., \& Haqiqi, F. (2021). PENERAPAN STANDAR AKUNTANSI DAN KUALITAS APARATUR TERHADAP LAPORAN KEUANGAN PEMERINTAH DAERAH (Studi Kasus pada Dinas Pekerjaan Umum dan Penataan Ruang Kabupaten Karimun). JURNAL CAFETARIA, 2(1), 13-24.

Tumanggor, R. O. 2018. Kepuasan Kerja dan Subjective Well-being dari Perspektif Psikologi Industri dan Organisasi. Yogyakarta: ANDI.

Wijono, S. 2010. Psikologi Industri dan Organisasi. Jakarta: Prenada Media.

Yusmalina, Y., Tegor, T., Haqiqi, F., Rosady, R. E., \& Azura, N. (2021). Comparative Analysis of Staretegi Traditional Market and Modern Markets of Consumer Valuation. International Journal of Multicultural and Multireligious Understanding, 8(11), 18-25. 